\title{
La Guerra del Paraguay y la historiografía argentina*
}

\author{
The Paraguayan War and the Argentine historiography
}

\author{
María Victoria Baratta \\ victoriabaratta@gmail.com \\ Becaria doctoral \\ Universidad de Buenos Aires \\ Dr. Marcelo Fitte, 1755/9 C \\ 1428 - Buenos Aires \\ Argentina
}

\section{Resumen}

La Guerra del Paraguay (1864-1870) fue un acontecimiento clave en el proceso de consolidación del Estado nacional argentino. El Paraguay enfrentó a los países signatarios de la Triple Alianza - Argentina, Brasil y Uruguay - en la contienda más sangrienta y larga de la historia de América Latina. En las décadas recientes en Argentina, nuevas perspectivas historiográficas sobre el siglo XIX han emergido y se ha experimentado una interesante renovación. Sin embargo, la Guerra del Paraguay no ha sido abordada con estas nuevas miradas. Proponemos entonces en esta instancia analizar la producción historiográfica argentina sobre la guerra y puntualizar además sobre los aportes de otras historiografías nacionales sobre el tema. Nuestro objetivo es contribuir a una nueva agenda de investigación sobre la guerra, identificar los vacíos temáticos y visualizar los desafíos que abre el estudio de esta contienda en la actual historiografía argentina del siglo XIX.

\section{Palabras clave}

Guerra; Historiografía; Argentina.

\begin{abstract}
The Paraguayan War (1864-1870) was a key event in the process of consolidation of the National State in Argentina. Together, Argentina, Brazil and Uruguay formed a triple alliance against Paraguay and fought the bloodiest and the longest war in the Latin American history. In the recent decades in Argentina, new historiographical perspectives about the 19th century have emerged, and an interesting renovation has been taking place. However, the Paraguayan War has not been thoroughly addressed by these new currents. We intend to analyze the Argentine historiographic production, along with contributions of other national historiographies about the topic. Our objective is to contribute to a new research agenda on the war, discussing thematic gaps and visualizing the challenges generated by the war in the current Argentine historiography of the 19th Century.
\end{abstract}

Keywords

War; Historiography; Argentina.

Recibido el: $1 / 4 / 2013$

Aprobado el: 15/5/2013

* Este estudio ha sido financiado por una beca doctoral del Consejo de Investigaciones Científicas y Técnicas de la Argentina (CONICET). 
Cuando a los argentinos se los interroga por una guerra en la que haya participado su país, la amplia mayoría hace referencia a la Guerra de Malvinas ocurrida entre abril y junio de 1982. La cercanía temporal, el recuerdo de lo vivido, el marco de la última dictadura militar y la continuación del conflicto por vía diplomática, mantienen esta contienda viva en el inconsciente colectivo. La Segunda Guerra Mundial no aparece en esa historia probablemente por la tardía y meramente simbólica o declarativa participación de nuestro país. Sin embargo, hubo otra guerra, mucho más larga y sangrienta, de la que sí participó el Estado nacional argentino de manera activa. Una guerra que pocos asocian a nuestra historia, una guerra que no muchos conocen, una guerra impensada, difícil de imaginar hoy, ya que enfrentó a los primigenios miembros del actual Mercosur.

La Guerra del Paraguay (también conocida como Guerra de la Triple Alianza, Guerra Grande o Guasú en Paraguay) fue la contienda más larga y sangrienta de toda la historia de América Latina. Enfrentó a la Triple Alianza - Argentina, Brasil y Uruguay - contra el Paraguay, duró más de cinco años (1864-1870) y se llevó consigo miles de muertos en batallas y epidemias, la mayoría de ellos, paraguayos. El país guaraní quedaría devastado económica y demográficamente e intervenido políticamente por los aliados. La lejanía en el tiempo, la incomodidad, la corrección política y hasta la vergüenza pudieron desdibujar a esta guerra del relato histórico nacional argentino.

Sin embargo, se trató de una guerra en la que el Estado argentino tuvo una activa participación en sus causas, desarrollo y consecuencias. La contienda se inició a partir de un conflicto en Uruguay que motivó la injerencia del Imperio del Brasil favoreciendo la invasión del General Venancio Flores. La acción de Flores fue además apoyada por el gobierno argentino presidido por el General Bartolomé Mitre. Brasil invadió el territorio uruguayo y el presidente del Paraguay Francisco Solano López salió en defensa del equilibrio del Río de la Plata que consideraba dañado. La captura el buque mercante brasileño Marqués de Olinda desató la guerra entre esos dos países. La guerra se extendería hasta el $1^{\circ}$ de marzo de 1870, fecha en que se terminó con la vida de Solano López.

Los inicios de la contienda involucraron al presidente de la República Argentina, a sus ministros y a varios líderes políticos opositores en el conflicto uruguayo. Argentina entró en la guerra con la constitución de una triple alianza con Brasil y Uruguay en contra de Paraguay el $1^{\circ}$ de mayo de 1865 . El General en jefe de esa alianza militar fue hasta promediar la contienda, nada más y nada menos que el Presidente de la República, Bartolomé Mitre. El reclutamiento para la lucha -si bien muy resistido- se realizaría en todo el país. Un fin temprano del conflicto estuvo en las manos del presidente en la conferencia de Yataití Corá (1866). La presencia argentina en el frente sería muy significativa hasta 1868. La contienda despertaría crecientes críticas en la opinión pública y resistencias armadas importantes. Los problemas internos forzarían al presidente a dejar su puesto de combate y regresar al país. Sin embargo, Domingo Faustino Sarmiento, su sucesor en la presidencia a partir de 1868 , tampoco cesaría la participación argentina en el conflicto. En relación a su población, Argentina tuvo un mayor porcentaje de bajas que Brasil y Uruguay, aunque mucho menor al desastre demográfico de Paraguay. 
Pero en otro sentido, probablemente el Estado liberal nacional argentino haya sido un gran vencedor de la contienda. La guerra le proporcionó una oportunidad de acallar la disidencia interna y de consolidar el Estado nacional centralizado y sus representaciones sobre la nacionalidad argentina.

Aún así la guerra es poco conocida en la Argentina, poco representada en los manuales escolares, y muchas veces cuando se la conoce se la asocia a un otro: "Fue Mitre", "Fueron los ingleses". La historiografía argentina y las interesantes renovaciones que la atraviesan, no han estado ajenas a esta tendencia porque prácticamente (salvo excepciones que mencionaremos) no han abordado el tema en los últimos 40 años. Nuestra investigación tiene como propósito primordial empezar a abrir un espacio que revierta esa tendencia en el ámbito académico. Nuestra línea de investigación específica se centra principalmente en el estudio de las representaciones de la nación durante la contienda (BARATTA 2012). Otras líneas de pesquisa se están desarrollando actualmente y algunas de nuestras propias líneas esperemos que excedan ese ámbito profesional. Un documental de la TV pública y algunas alusiones en el discurso presidencial dan cuenta de cierto movimiento de interés en la guerra, probablemente motorizado por los bríos de los últimos tiempos de entidades como el Mercosur y la Unasur.

Historiadores influyentes han deslizado en sus trabajos la idea de una íntima relación entre la guerra y la identidad nacional argentina. José Luis Romero escribió en su trabajo Las ideas políticas en Argentina

También contribuyó eficazmente a asentar el principio de la unidad nacional la Guerra del Paraguay, desencadenada en 1865. Un esfuerzo ciclópeo realizó entonces todo el país para afrontar el conflicto, y al cabo de cinco años había surgido, sobre las cenizas del sacrificio común, una idea más viva de la comunidad argentina (ROMERO 1956, p. 160-161).

Sin embargo Romero no estaba estudiando la guerra por lo que no fundamenta ni desarrolla más a fondo su hipótesis.

Por otra parte, en un trabajo que sí habla sobre la guerra, Leslie Bethell sentencia que

En el balance, la guerra había contribuido positivamente a la consolidación nacional: Entre Ríos y Corrientes no rompieron filas; las rebeliones montoneras en varias provincias fueron suprimidas; Buenos Aires fue aceptada como capital indiscutida de una república unificada, y la identidad nacional quedó considerablemente fortalecida (BETHELL 1995, p. 16).

No obstante Bethell no analiza el caso argentino, sino la guerra en general y sobre todo el papel de Gran Bretaña. Por esta razón nuevamente tenemos una afirmación que carece de una investigación minuciosa que la sustente.

En el caso de Brasil, José Murilo de Carvalho considera que la Guerra del Paraguay es un período privilegiado para revelar las representaciones de su patria. Más aún sostiene que 
A pesar de las dificultades en formar una imagen de nación que incorporase la realidad de la población, el Imperio vivió una experiencia colectiva que fue el factor más importante de la creación de la identidad nacional desde la independencia hasta 1930. Se trata de la Guerra del Paraguay (DE CARVALHO 1994, p. 410).

En esta instancia particular proponemos debatir el lugar de esta guerra en la historiografía argentina. En primer lugar repasaremos la historiografía argentina que exaltó la participación de nuestro país y la cruzada contra Francisco Solano López. Luego analizaremos la reacción revisionista a esas primeras miradas. Enseguida daremos un vistazo a los estudios recientes sobre la contienda en la historiografía regional y mundial, con énfasis en el caso brasileño. Concluiremos con un repaso sobre la historiografía argentina reciente sobre la guerra.

\section{Todos los caminos conducen a López}

Los trabajos sobre la contienda en la Argentina se han detenido principalmente en el examen de sus causas, consecuencias y responsables, en los aspectos político-diplomáticos y en la narración de los acontecimientos militares. Un breve repaso por estos abordajes comienza con los escritos que vieron la luz durante la contienda o en los momentos inmediatamente posteriores. Empezamos nuestro relato mencionando los escritos publicados en Buenos Aires en el devenir de la contienda. La ya clásica obra de José Manuel Estrada crítica sobre el Paraguay (ESTRADA 1865), los escritos militantes opositores a la contienda de Juan Bautista Alberdi, Carlos Guido y Spano, Olegario Víctor Andrade y Miguel Navarro Viola, muchos de ellos publicados en el periódico La América editado en Buenos Aires durante 1866. Hacia el final de la guerra aparecería la Historia de la guerra del Paraguay del ingeniero inglés George Thompson, quien estuvo del lado del frente paraguayo en el cual construyó algunas importantes fortificaciones (THOMPSON 1869). Inmediatamente después se publicaría en nuestro país el relato del farmacéutico George Masterman sobre la esencia del ser paraguayo y su gobierno. Ambos trabajos fueron críticos con Francisco Solano López. Memorias de la guerra pueden encontrarse también en la obra de del propio Bartolomé Mitre (1911), los diarios de León Palleja (1865) y en la pintura de Cándido López, Adolph Methfessel y Juan Manuel Blanes, además de la publicación del Álbum de la Guerra del Paraguay en 1893.

Sin embargo podríamos situar el comienzo de una historiografía argentina sobre la guerra hacia fines del siglo XIX con las obras de Vicente Fidel López (1896) y Mariano Pelliza (1897) quienes explicaron el desencadenamiento de la guerra como una respuesta a la agresión de un único responsable: Francisco Solano López. El fin del enfrentamiento significó la liberación del pueblo paraguayo de la barbarie impuesta por los gobiernos tiránicos que lo habían mantenido aislado de las naciones civilizadas. Esta postura fue difundida en un primer momento en los países vencedores y también en el Paraguay.

A comienzos del siglo XX, Ernesto Quesada, intelectual argentino publicaría algunos escritos con tímidas críticas a la alianza a principios del siglo XX (QUESADA 1902). De todas maneras su postura sería aún minoritaria. A esta reacción no 
dominante dentro de las posturas nacionalistas en nuestro país se sumarían las obras de reivindicación de Juan Bautista Alberdi en la pluma de David Peña: "En defensa de Alberdi" de 1911 y "La traición de Alberdi" de 1919 (PEÑA 1965). En el país guaraní una contra-historia más difundida sobre la guerra empezaría a desarrollarse muy tempranamente. Los trabajos de Liliana Brezzo (BREZZO 2004) constituyen una referencia ineludible en ese sentido, en los cuales se analizan las obras de Juan O'Leary, Manuel Domínguez, Ignacio Pane y Natalicio González, entre otros. En Uruguay durante las primeras décadas del siglo XX, las obras de Luis Alberto de Herrera configurarían lo que serían los orígenes del relato revisionista en el país oriental. Laura Reali (2006) ha llamado también la atención sobre el intercambio de Herrera con Ernesto Quesada

El proyecto de Estanislao Zeballos de redactar una historia general sobre la contienda quedaría trunco, acción que sí logra llevar a cabo el Coronel Juan Beverina al publicar una historia general de tinte militar sobre la temática (BEVERINA 1921). Se trató en primera instancia de un compendio preparado para ser publicado en un número extraordinario del periódico porteño La Nación (sucesor de La Nación Argentina, el diario mitrista contemporáneo a la guerra) editado como conmemoración del primer centenario del nacimiento de Bartolomé Mitre el 26 de junio de ese año. La publicación en la que luego se convertiría no podía entonces comenzar de otra forma que con un homenaje enaltecedor de la figura de Mitre en su doble papel de Presidente de la República y General en Jefe de los Ejércitos Aliados durante los primeros años de la guerra. De todas maneras, Beverina se esfuerza por tratar de dejar en claro que su rol de historiador le pide un exacto conocimiento, sin prejuicios ni apasionamientos. Beverina cree que han pasado los suficientes años como para elaborar un relato histórico imparcial sobre la contienda. Sin embargo su obra, relato típicamente militar dividido en causas diplomáticas y luego en batallas y cartografía final, sostiene una visión clara de la guerra, que no difiere sustancialmente de las de Pelliza y V. F. López. El desencadenante de la contienda fue la agresión del presidente paraguayo al imperio brasileño y Beverina lo sustenta con una descripción histórica del Paraguay post independencia. Esa descripción contiene el calificativo a sus gobernantes como tiranos. Llama la atención, en disonancia con esta postura clásica, un reconocimiento a cierta injerencia de la prensa porteña sobre la incorrecta decisión de Solano López. Pero de todas maneras hasta aquí no hay más que el reconocimiento de una causa unilateral de la guerra y ella está en Paraguay. Esa es básicamente la intención de la obra, reivindicar la figura de Mitre y acusar al Paraguay como principal responsable de la contienda. En esta época también se edita la novela histórica de Manuel Gálvez (GÁLVEZ 1928-1932).

Hacia finales de la década de 1930 Ramón Cárcano analizó los aspectos político y diplomáticos, enfatizando el rol cuasi heroico de Mitre (CÁRCANO 1938). Este autor enmarcó la contienda como una lucha facciosa, prolongación del proceso de consolidación del Estado nacional (de la batalla de Caseros en 1852 a la de Pavón en 1861 en su visión) y aún más ampliamente en una lógica de larga duración que abarcaba las disputas entre el imperio español y 
portugués hasta las independencias. Cárcano sostiene que la concordia entre Brasil y Argentina es un punto esencial para el desarrollo de América del Sur, aunque critica las ansias de expansionismo brasileño. Además considera que la actitud del caudillo federal entrerriano Justo José de Urquiza de no forjar alianza con el Paraguay como la culminación de su obra: la constitución y la consolidación definitiva de la República Argentina. Fuera de la Argentina el trabajo de Pelham Horton Box mantiene también una línea diplomática (BOX 1958).

En suma, con sus diferencias y matices, la perspectiva del relato militar y/o diplomático, algunas veces dedicado a establecer causas y otras a edificar héroes que contribuyan a un relato nacional cuasi épico -que centró su mirada en responsabilizar casi exclusivamente a Francisco Solano López por la guerra-, fue la dominante en la historiografía argentina hasta la década de 1950. Una postura militar diplomática similar se divulgaba también en Brasil con la obra de Fragoso (1956), pero algo muy diferente empezaba a gestarse en Paraguay y Uruguay. Algo de ese movimiento, aunque sobre todo una lógica propia, estará presente en la fuerte reacción historiográfica que analizaremos a continuación.

\section{El revisionismo como reacción}

Si bien en Paraguay había comenzado a difundirse una revisión de la historia sobre la guerra, no será hasta la década de 1950 que comiencen a editarse publicaciones de autores argentinos que propondrán una reacción ante la historia mitrista, diplomática y/o militar. En el país guaraní esta contra-historia empezaría a desarrollarse muy tempranamente, en los albores del siglo XX (BREZZO 2004) más ligada a un nacionalismo conservador. En cambio en Argentina, el desarrollo de los partidos de izquierda y del peronismo proporcionaron una oportunidad y los interrogantes para llevar adelante una contra-historia en nuestro país, y el episodio de la Guerra del Paraguay no quedó exenta de esa revisión. Enrique Rivera, militante de la izquierda nacional argentina que apoyó al peronismo desde la distancia ideológica que lo separaba, publicó en 1954 José Hernández y La Guerra del Paraguay por Editorial Indoamérica (RIVERA 1954). Rivera sostiene allí que la Guerra de la Triple Alianza fue llevada adelante por el capitalismo extranjero y sus agentes, las oligarquías porteña y uruguaya y el imperio brasileño en contra del pueblo del Paraguay y también de la Argentina. El resultado fue la destrucción del modelo de país desarrollado por los López y la reducción de nuestro país a la condición semi-colonial. Rivera afirma también que la contienda fue el primer genocidio de la América independiente. Si bien el título del libro se centra en la figura de José Hernández y su oposición a la guerra, el lugar que ocupa el tema en el mismo es reducido y se trata de un racconto que sitúa el origen nacional antes de la revolución de Mayo y desarrolla la historia hasta el mitrismo. Durante esa misma década, aunque publicado con posterioridad a su temprana muerte, el historiador trotskista Milcíades Peña comienza a producir su inconclusa Historia del pueblo argentino. La misma contiene un segmento dedicado a la era de Mitre que lleva el sugerente subtítulo "De Caseros a la Guerra de la Triple Infamia", lo cual denotaba su postura frente a la misma y quedaría plasmado como título alternativo de la contienda en 
el inconsciente colectivo. Para Peña la guerra fue un momento conclusivo de la imposición del capital burgués comercial porteño que configuró un estado nacional liberal unitario. Hay que destacar que él no abogará por la tesis de un papel complotador de Gran Bretaña en el conflicto (PEÑA 1968).

A partir de la década de 1960, estas visiones comienzan a difundirse, multiplicarse e imponerse hasta el punto que continúan hasta hoy erigiéndose como las dominantes en el inconsciente colectivo argentino. Estas posturas, aunque con sus diferencias de matices, se agruparon en torno a la denominación de revisionismo histórico, en su búsqueda de impugnación a la tradición liberal mitrista. A nivel general, la contienda es entendida como una agresión imperialista británica, cuyos títeres son el imperio del Brasil y Argentina, contra una nación autárquica y desarrollada (CHAVEZ 1966; POMER 1968; ROSA 1965; GARCÍA MELLID 1964; ORTEGA PEÑA; DUHALDE 1967; DE PAOLI; MERCADO 1973; GALASSO 1975). Las hipótesis revisionistas postulaban que Gran Bretaña había provocado la guerra para asegurarse en Paraguay un mercado rentable para sus exportaciones y destruir así la economía estatista paraguaya. También circuló la idea de que Gran Bretaña buscaba en Paraguay el algodón que la guerra civil en Estados Unidos le estaba negando.

En nuestro país las dos visiones más difundidas de esta corriente fueron las de José María Rosa y León Pomer. El historiador brasileño Ricardo Salles (SALLES 1990) las ha dividido en la versión de la unidad de América hispánica (ilustrada con José María Rosa y su obra La Guerra del Paraguay y las Montoneras Argentinas) y la versión de la intervención imperialista (las diferentes obras de León Pomer, reproducida también por Julio José Chiavenatto en Brasil). En el caso de Rosa -cuya obra sobre la guerra excede ese particular libro aunque se trata del más emblemático- se puede reconocer el doble mérito de dar voz a los vencidos y además que éste también no equipara los intereses del imperio brasileño con los del imperio británico, con relaciones diplomáticas cortadas al momento de la guerra. Sin embargo Rosa no matiza en el caso argentino porque considera a todos los gobiernos de Mitre en adelante como unos traidores que han entregado el país a los capitales extranjeros. La profusa documentación que Rosa utiliza es vista muy desde su presente, desde los movimientos antiimperialistas de los años 1950 y 1960. Es una simplificación que invierte las simplificaciones tradicionales. Este proyecto de unidad trasnacional que el autor proponía carecía de bases sociales y económicas reales y obturaba las particularidades sub-regionales.

La versión de la intervención imperialista desarrollada por León Pomer en La Guerra del Paraguay, Gran negocio postula un Paraguay con un camino de desarrollo original, autónomo, autosuficiente, nacionalista y antiimperialista (POMER 1968). Pomer denuncia el rol de Gran Bretaña en el conflicto y sus vínculos con el mitrismo, el Imperio del Brasil y los colorados del Uruguay. Considera que la guerra fue una afrenta ignominiosa y un genocidio de un pueblo hermano y heroico. Su trabajo busca poner de relieve los negociados encubiertos por la fachada moral y pretendidamente neutral de la historia mitrista. Para ello comienza el relato en la Gran Bretaña del siglo XVI y luego profundiza en el 
modelo de un Paraguay "insólito" en el siglo XIX de la Cuenca del Plata, modelo incompatible con los intereses británicos y sus brazos armados en esta región. Salles utiliza los datos del propio Pomer y llega a la conclusión de que la pauta de importaciones paraguayas no era muy diferente de la de sus vecinos. No existió una propuesta de construcción de una nación independiente. Sostiene además que el análisis de Pomer reduce las relaciones políticas a las relaciones económicas y además iguala los intereses del imperio británico con el brasileño, cuyas relaciones estaban en conflicto para esa época. En 1986 Pomer publicaría Cinco años de guerra civil, libro que demuestra con abundante y contundente documentación la resistencia popular a la guerra en nuestro país (POMER 1986). En 2008 llegaría una tercera edición de la primera obra de Pomer.

Otras obras que reprodujeron estas mismas hipótesis fueron las de Fermín Chávez, García Mellid, Ortega Peña y Duhalde, mientras que De Paoli y Mercado puntualizaron que las rebeliones internas como las de Felipe Varela no se hicieron contra el Imperio Británico como lo afirmaron Ortega Peña y Duhalde. Estos últimos también prologaron una reedición de la obra de David Peña. En 1962 son publicados por Ediciones de la Patria Grande los escritos de Juan Bautista Alberdi durante la contienda prologados con un compendio de estas mismas ideas revisionistas, algo diferentes a las del autor de las Bases.

Reconocemos el aporte de dar voz a los vencidos, comprender la contienda en un marco histórico y geográfico amplio, desterrar el mito de la neutralidad y poner luz sobre la actuación de los aliados. De todas maneras y con sus matices, esta contra-historia propuso centrarse en las mismas temáticas que su antecesora, buscar orígenes, causas, responsables, héroes y culpables. Propuso dar vuelta la moneda y mostrar su otra cara. Allí radicó también su éxito y su limitación. Un éxito comprensible en un contexto de guerra fría, dictaduras militares que propiciaban el combate ideológico desde la izquierda y el peronismo y la analogía de una Cuba independiente y aislada con el proto-socialismo Paraguayo pre-guerra. Pero el éxito superó la época. Porque hasta hoy perduran sus postulados más fuertes en nuestro país. El inconciente colectivo argentino ha retenido sus postulados más fuertes y muchos de estos libros se han reeditado en los últimos años.

\section{Por fuera de la dicotomía}

Según Leslie Bethell, desde fines de la década de 1970 la guerra ha recibido muy poca atención por parte de los historiadores. Un conjunto de temas promisorios aguardan ser explorados: "La Guerra del Paraguay espera su historia moderna" (BETHELL 1996, p. 19). Si bien existen trabajos recientes innovadores -en los que se busca echar por tierra las ideas de revisionistas-, los más influyentes corresponden a la historiografía brasileña.

En 1989 la Revista paraguaya de Sociología publica un interesante artículo de Diego Abente Brun "La Guerra de la Triple Alianza: tres modelos explicativos" en el cual a partir de un análisis característico de las ciencias sociales, se refutan principalmente las de equilibrio de poder que fue argumento del mismo Solano López y la teoría imperialista, baluarte de la tradición revisionista (ABENTE BRUN 1989). 
El trabajo de Ricardo Salles marca un punto de inflexión en la historiografía de los países involucrados. Salles siente que debe saldar una deuda; la guerra es un hecho desconocido, olvidado, poco conocido para la mayoría de la población y descuidado en los últimos años por la historiografía. Si bien el objetivo del autor con este libro es comprender la formación de un ejército nacional profesional y sus relaciones con la sociedad, considera inevitable interrogarse respecto del origen del conflicto. Para ello le resulta imprescindible repasar las visiones historiográficas que lo han abordado: la que denomina tradicional y, sobre todo, la revisionista. Salles las distingue para hacer su crítica, pero deja en claro que algo las liga: las simplificaciones. La crítica principal es su reduccionismo ya que sobredimensiona el papel de los ingleses y menosprecia el papel de los actores palatinos, aunque no se trata de negar las vinculaciones. Salles postula que el reclutamiento para la guerra fue exitoso y afectó al conjunto de la sociedad. Estima que no más de un $10 \%$ de los soldados eran esclavos. La hipótesis principal del libro sostiene que la presencia del esclavo como Voluntario de la Patria y Héroe Nacional contribuyó a minar la estructura social esclavista, al ser una manifestación de la contradicción entre la estructura político-jurídica liberal del Imperio y su base esclavista. La participación de los esclavos en el ejército garantizó, al menos para la parte de la población servil involucrada, alguna forma de reconocimiento y un lugar de interlocución. Su incorporación en un proyecto de realización hegemónica de la Corona y de la clase dominante implicaba necesariamente asimilar algunos de sus propios intereses a ese

106 proyecto. Se plasma la contradicción de los esclavos accediendo en escala ampliada a un derecho y un deber de la ciudadanía. Los años que siguieron a la guerra se caracterizaron por rebeliones intensificadas, distintas a las anteriores, por la búsqueda de esos derechos. Salles concluye entonces que la presencia de los esclavos en el ejército tuvo entonces profundos efectos sobre la crisis y el derrumbe del Imperio. A partir de la lectura de fuentes literarias de la época, sostiene que la guerra no fue popular y probablemente la mayoría de los reclutados fueran a la fuerza. Pero significó un esfuerzo a nivel nacional, material, ideológico, humano y moral, que terminó de provocar un sentido de unidad nacional en la población.

Por otra parte la historiografía brasileña reciente también se dedicó a analizar representaciones de la prensa en la guerra, haciendo foco en las imágenes. André Toral analizó la prensa y la guerra de imágenes paralela a la guerra material que buscó destruir al enemigo y levantar la moral propia (TORAL 2001). Toral adscribe a la revisión de la historia de la guerra propuesta por Salles y Abente Brun y analiza fundamentalmente prensa brasileña (de la cual sostiene que fue algo crítica con el gobierno imperial) y paraguaya (prácticamente adicta a Solano López). La prensa argentina de la época a excepción de El Mosquito y El Correo del Domingo, no apeló a las imágenes durante la contienda. En $A$ Batalha de papel Mauro César Silveria sostiene que la prensa ilustrada brasilera se encargó de demonizar al enemigo (SILVERIA 2005). Las apelaciones al pueblo paraguayo lo ligaban con una comunidad extraña, rara y servil. Sin embargo no son solamente las particularidades culturales las que motivan la 
atención de los periódicos. Una tradición política comunera es tomada como extraña y representativa del país guaraní. Silveira se cuida en esta instancia de no adherir a la visión idealizada del Paraguay pre-guerra, característica de las posturas revisionistas ni tampoco de denostarlo. Aunque no se trataba de una potencia, el Paraguay de la primera mitad del siglo XIX se caracterizaba por una combinación de aislamiento político y cierto nivel de desarrollo social y económico. La figura de Solano López domina ampliamente las caricaturas de los periódicos satíricos de la Corte. Se intentaba desde la prensa brasileña atribuirle a López la responsabilidad de la guerra y describirlo como un bárbaro, déspota, furioso, loco, enfermo y feroz. La encarnación del mal en Solano López era la imagen necesaria para una sociedad eminentemente católica; el presidente paraguayo era el mismo diablo.

El trabajo de Silveira propone además el interesante ejercicio de enunciar una postura crítica sobre la guerra, pero sin por ello renunciar a comprender su racionalidad ni adscribir a las tesis revisionistas. Además por su formación en comunicación, Silveira rastrea la permanencia de algunos estereotipos sobre los paraguayos en la prensa brasileña del presente. De todas maneras, ninguno de los trabajos escapa a una tendencia "brasileño-céntrica" que describe la contienda como una lucha militar entre Paraguay y Brasil. Argentina aparece apenas como co-aliada y Uruguay tiene un papel simbólico. Es cierto que en los últimos años de la guerra la presencia argentina fue menor. Pero no así en lo que refiere a los desencadenantes y los primeros años de la contienda. La falta de estudios novedosos en nuestra historiografía con los cuales dialogar también contribuye a profundizar este aspecto.

Silveria también dedica unas páginas a otra tarea casi obligada del historiador actual de la guerra, como también lo hicieron Salles y Toral: poner en cuestión el papel de Gran Bretaña en la misma y dar por tierra la posibilidad de que haya sido la responsable. La publicación del tratado de la triple alianza por parte de la diplomacia inglesa, sus conflictos con el Brasil, la debilidad de las hipótesis del mercado del algodón y los mismos conflictos regionales ya dan sobrada muestra de que aún cuando haya sido una beneficiada indiscutida de los resultados no hay pruebas sólidas de su responsabilidad como desencadenante del conflicto. En este sentido, Silveira reivindica la postura de Milcíades Peña al respecto.

El libro de un autor brasileño que provocó gran revuelo e influencia en la historiografía académica y también en la opinión pública argentina fue Maldita Guerra de Francisco Doratioto, obra de más de 600 páginas que lleva como subtítulo Nueva Historia de la Guerra del Paraguay. El éxito fue tal que el libro fue editado en español en Buenos Aires por Emecé en 2004. Se trata de un ambicioso trabajo de investigación que está marcado por una visión diplomática liberal brasileña. Doratioto ya tenía en su haber trabajos que postulaban una visión similar a la que despliega en Maldita Guerra desde 1991. La guerra es entendida en su óptica como resultado de las contradicciones platinas y teniendo como objetivo último la consolidación de los Estados nacionales de la región. Sin embargo la guerra no era la única salida necesaria a los conflictos que se originaron en Uruguay y si tuvo lugar finalmente fue porque interesaba a 
todos los involucrados que así sea. Todos previnieron un conflicto rápido que finalmente no se produjo de esa manera. La detallada investigación de Doratioto proporciona así explicaciones al inicio de la contienda que pretenden en principio alejarse de las dicotomías explicativas. El caudal de información y el detalle de las fuentes hacen de este libro un aporte insoslayable. El historiador Mário Maestri sostiene que la obra de Doratioto constituye una suerte de restauración historiográfica y que como aquellos primeros estudiosos de la guerra, esgrime una pretendida neutralidad que no existe (MAESTRI 2013).

La historiografía paraguaya tiene dificultades en escapar de la lógica lopismoantilopismo. Constituyen loables excepciones los trabajos de Guido Rodríguez Alcalá (RODRÍGUEZ ALCALÁ 2007; 2010) con sus críticas al revisionismo paraguayo y la publicación de documentos de las víctimas paraguayas de los tribunales de Francisco Solano López, Ana Barreto Valinotti con su historia de las mujeres (VALINOTTI, 2012) y todos los trabajos de Liliana Brezzo sobre la historiografía. Podemos sumar las renovaciones que presentan las miradas de Ignacio Telesca (2010), Milda Rivarola (1988) y Bárbara Pottash (1996) aunque no siempre centrados en la temática guerra. El fin de la dictadura en el país guaraní propicia nuevas investigaciones y metodologías que procuran comprender la guerra en sus propios términos sin demonizar a Francisco Solano López, ni tampoco elevarlo a la categoría de héroe que quiso esgrimirle el revisionismo. Revisionismo que mientras en Argentina estuvo identificado con la resistencia peronista y la de izquierda, en Paraguay fue en cambio el relato constructor de la 108 dictadura del General Alfredo Stroessner. Por otra parte, la historiografía uruguaya reciente sobre la cuestión es escasa, quizás motivada por la participación casi simbólica que terminará teniendo la Banda Oriental aunque algo inexplicable porque el origen de la guerra fue allí. Se encuentran algunos relatos heroicos sobre Paysandú y libros de fotografías (VIGIL y VALLARINO 2007).

Fuera de la historiografía de los países involucrados, no podemos eludir los recientes trabajos de Thomas Whigham (KRAAY; WHIGHAM 2004; WHIGHAM 2010; 2011; 2012) y Luc Capdevila (CAPDEVILA 2010) quienes se especializan fundamentalmente en el caso paraguayo. Capdevila parte de la correcta convicción de que sería imposible comprender el Paraguay actual sin tomar en cuenta esta penosa contienda que terminó hace ya más de 140 años. Por ello se ha propuesto realizar un ensayo que conecte el desarrollo de la guerra y la memoria construida a partir de su finalización. Lo que la obra logra analizar con detalle y precisión es cómo el espacio de lo cotidiano en el Paraguay está inundado de memoria sobre la contienda. Esta guerra fue una bisagra en tanto puede considerarse el cierre de los conflictos de independencia y a su vez apertura y consolidación de los estados nacionales y sus fronteras. También se busca enmarcarla en un proceso de totalización de las guerras internacionales de la era industrial. Sin embargo se sostiene que se trata de de una guerra americana, es decir de un conflicto regional.

En el Paraguay actual, calles, avenidas, la moneda, los billetes, el nombre de las compañías de ómnibus, todo remite a la gran guerra. El mito del país de las mujeres que Paraguay detentó, lejos está de asemejarse al paraíso de Mahoma 
sino más a un país que vivió un Holocausto masculino y que debe resurgir de sus cenizas como el Ave Fénix. Sin embargo la historia posterior a la guerra es una historia de hombres; políticos, militares, intelectuales y propietarios. La disputa por la memoria se centra también en la figura del mariscal: como mencionamos el encono de lopistas y antilopistas sigue vigente al día de hoy y continúa dominando la visión del pasado en el vecino país. La caída de la dictadura no ha provocado todavía nuevos interrogantes y miradas sobre esta guerra en la sociedad paraguaya sino que ha reavivado el viejo debate lopismoantilopismo. La retórica periodística reproduce esta lógica maniquea.

Asimismo como apuntamos se tornas ineludibles los trabajos del historiador estadounidense Thomas Whigham, tanto la compilación que editó junto con Hendrik Kraay, I Die with my Country, como la monumental historia total de la guerra La Guerra de la Triple Alianza en 3 volúmenes. El autor ubica la contienda como punto culminante de las tensiones que se acentuaron después de la independencia entre España y Portugal, cuyo desencadenante fue la disolución del Virreinato del Río de la Plata y la formación y la consolidación del Imperio del Brasil. Whigham hace una analogía de la contienda con la contemporánea guerra civil americana en tanto ambas terminarían en la consolidación de las incipientes naciones de nuestra región. Analiza la guerra y sus consecuencias en los cuatro países involucrados, con énfasis en Paraguay, buscando desterrar también los mitos revisionistas que responsabilizaron a Gran Bretaña, intentando comprenderla dentro de un marco regional y atendiendo a la lógica de sus actores.

De esta renovación de la historiografía, en la Argentina solo se han editado las obras de Capdevila con escasa circulación y Doratioto, siendo ésta última la de mayor repercusión y también una recopilación. Además se ha editado un estudio crítico de la correspondencia de Juan Bautista Alberdi y Gregorio Benites (LOIS; PAGLIAI, 2007). Si el investigador local quiere acceder a toda la bibliografía, debe traspasar las fronteras, y en muchos casos, leer en portugués o inglés. El público en general ha tenido entonces acceso limitado a estas renovaciones por lo que los diálogos entre historiografías recientes entre países de la región son desde Argentina hoy, limitados. La posibilidad de intercambio con el Paraguay se facilita en provincias más cercanas como Corrientes o a través de investigadores argentinos que estudian ese país como Telesca o Brezzo. Desde Buenos Aires el gran público solo puede acceder a los libros editados en Asunción una vez al año en la Feria del Libro. Las obras más difundidas de la historiografía argentina sobre la guerra en los países de la región han sido las del revisionismo analizado que ha inspirado a muchos otros autores fuera de nuestro país (CHIAVENATTO 1979).

\section{La guerra olvidada}

En cuanto a la historiografía reciente en nuestro país sobre el tema, es sintomático que en el volumen de la Nueva Historia Argentina correspondiente al período 1852-1880, la Guerra del Paraguay aparezca solo escasamente mencionada y en artículos que no la tienen en el centro de su análisis (BONAUDO 1999). Asimismo Alberto Lettieri abordó en su libro La República de las Instituciones el período comprendido entre 1852 y 1880 , pero la guerra 
es poco analizada ya que su interés fundamental radica en el estudio de la década de 1870 (LETTIERI 2000). Afortunadamente contamos con dos nuevas historias generales del período que analizan la contienda retomando los avances generales que mencionamos en el apartado anterior, aunque entre una lista de otros temas (GARAVAGLIA; FRADKIN 2012; SABATO 2012). Podemos agregar el tratamiento de la guerra que Ariel de la Fuente hace en parte de su libro sobre caudillos en La Rioja (DE LA FUENTE 2007). Desde una tradición historiográfica diferente a la de la Nueva Historia Argentina, León Pomer escribe en el prólogo a la reciente reedición de su obra

No puedo ocultar lo que me parece significativo: la poca o ninguna importancia que los historiadores universitarios le dan a la guerra como objeto de investigación, siendo que fue un momento capital de la constitución del Estado argentino y dio un cuantioso aporte a la casi eliminación de un pueblo hermano (POMER 2008, p. 9).

La afirmación de Bethell es entonces más que pertinente para el caso argentino, participante decisivo en el desarrollo de la guerra. Los recientes trabajos sobre la temática en nuestro país entonces han sido escasos y no se han detenido en la problemática de la identidad nacional desde las elites argentinas y apenas han abordado las representaciones en general. La historiografía argentina reciente sobre la guerra más prolífica se encuentra en Corrientes, escenario argentino de la contienda. Dardo Ramírez Braschi estudió el impacto de la guerra en la provincia a través del análisis de la prensa (RAMÍREZ BRASCHI 2004). En un trabajo que sucinta gran interés por tratarse del escenario argentino de la contienda y que demuestra el incómodo lugar que los correntinos mantuvieron durante la contienda, desde los aliados al mitrismo, hasta los cómplices con el Paraguay y quienes fueron acusados formalmente de traidores. María Gabriela Quiñonez también trabajó un tema caro a la provincia y la contienda, el caso de las cautivas (QUIÑONEZ 2012). Con este material, Quiñonez se encargó de asesorar la publicación de "Cautivas" una novela de Gabriela Saidón publicada en 2008 por Editorial Planeta que despertó gran polémica en Corrientes en su presentación, en la que también se encontraba como expositor el escritor paraguayo Guido Rodríguez Alcalá. Pablo Buchbinder abordó la inserción de Corrientes en el proceso de construcción del estado nacional y su análisis incluye La Guerra del Paraguay (BUCHBINDER 2004).

Por otra parte encontramos además editados en Buenos Aires el libro de Miguel Ángel de Marco quien estudia con detalle la vida cotidiana en el frente (DE MARCO 2003). También se editó el trabajo de Leonardo Castagnino en el que se repiten los postulados de la historiografía revisionista en un relato más de tinte de divulgación (CASTAGNINO 2010). Sumamos también en esta tendencia revisionista las reediciones recientes de los libros de Pomer en 2008, de Rivera sobre José Hernández en 2007 y Galasso sobre Felipe Varela en 2011 por editorial Colihue. También otro libro que él junto con su equipo de investigación publicaron en 2012 sobre Varela (GALASSO 2012). Si bien Liliana Brezzo analizó en un breve trabajo las representaciones de los argentinos, lo hizo solo desde la mirada de 
los manuales paraguayos (y no desde las mismas elites argentinas), buscando centrarse fundamentalmente en la historia del vecino país y sus relaciones de integración con Argentina (BREZZO 2002). Además el período estudiado no se focaliza exclusivamente en la guerra, sino que parte de los efectos posteriores a la misma: la destrucción y reconstrucción de la memoria nacional paraguaya y las relaciones bilaterales principalmente durante el siglo XX. Hacia fines de 2008 El Centro de Estudios Latinoamericanos de la Universidad Nacional de San Martín organizó su quinto encuentro anual. Esta vez el tema elegido fue "La Guerra del Paraguay: historiografías, representaciones y contextos". Los trabajos de las jornadas están publicados on line en la Revista Nuevos Mundos. La mayoría de los trabajos argentinos allí presentados corresponden a destacados académicos pero que no se dedican específicamente al tema de la guerra. La Guerra tomó estado público durante 2012 cuando se emitió en la TV Pública el documental Guerra Guasú, que de alguna manera reivindicó la postura revisionista aunque propuso interesantes debates públicos con especialistas de diferentes posiciones historiográficas. El tema fue abordado tangencialmente en algunos discursos de la presidenta de la Nación Cristina Fernández de Kirchner, también con la apelación a algunas consignas revisionistas. En 2014 y 2015 se cumplirán 150 años del inicio de la guerra y esperemos que la fecha pueda abrir el debate historiográfico académico y público.

Analizamos la historiografía renovada sobre la contienda fuera de la Argentina como una manera de poder dar a conocer las líneas de investigación y entablar diálogos a futuro. Sostenemos que el caso brasileño abre muchas líneas de investigación que pueden ser retomadas para asuntos del caso argentino y por ello nos hemos detenido en su descripción ya que los avances allí son los más notorios entre los países que participaron de la contienda. Celebramos además la reapertura de las investigaciones históricas en el Paraguay democrático y esperamos que sigan desarrollándose nuevas miradas allí y también las esperamos en el Uruguay.

El estudio de los lenguajes y conceptos políticos (soberanía, civilización, barbarie, libertad, pueblo), de los sectores populares, de la formación de milicias y el ejército, de la prensa, de las mujeres, las dinámicas políticas, las implicancias socio-económicas, del papel de la religiosidad, de los mecanismos de justicia, de la memoria y de la constitución de la ciudadanía, entre otros, son tópicos que hoy recorren con vigor la historiografía del siglo XIX argentina. La Guerra del Paraguay, tan incómoda y políticamente incorrecta, los espera. La guerra del Paraguay también fue argentina con todas sus resistencias y oposiciones. Constituyó un evento crucial en la consolidación del Estado nacional y es parte de su historia, aunque incomode. Mientras tanto continúa presa del olvido o de los razonamientos maniqueos y anacrónicos. No pretendemos esgrimir que la historia tiene pretensiones de neutralidad absoluta (en la que no creemos ya que son múltiples los factores que condicionan la tarea del investigador), ni tampoco hacer un trabajo cuyo objetivo sea político. Esperamos un análisis de esta guerra tan dolorosa y polémica evitando las dicotomías, sin tomar con literalidad las fuentes, desterrando teorías conspirativas y sin glorificar ni 
diabolizar conductas humanas. No obstante el fin de los juicios morales, no implica que no se pueda sentar una postura como Pierre Vidal Naquet lo dijo sobre la esclavitud. La guerra del Paraguay fue un triste evento que dejó miles de muertos y problemas económicos graves que no alabamos, ni queremos que vuelvan a repetirse en nuestra región. Para ello nada peor que negarla de la propia historia. Sin embargo no pecamos de ingenuos y sabemos que la violencia y la política no eran incompatibles durante el siglo XIX, pero algunas prácticas de la guerra, su duración y crueldad fueron denunciadas en ese mismo momento y probablemente pudieran haberse evitado.

\section{Referencias bibliográficas}

ABENTE BRUN, Diego. La Guerra de la Triple Alianza: tres modelos explicativos. Revista Paraguaya de Sociología. Asunción: p. 175-198, enero-abril de 1989.

BARATTA, María Victoria. La identidad nacional argentina durante la Guerra del Paraguay. Representaciones, lenguajes políticos y conceptos en el diario La Nación Argentina (1862-1870). Almanack, n. 3, p. 82-98, 2012.

BARRETO VALINOTTI, Ana. Voces de mujer en la historia paraguaya: 200 años después. Asunción: Asociación Trinidad, 2012.

BETHELL, Leslie (org). A guerra do Paraguai: 130 anos depois. Río de Janeiro: Relume Dumará, 1995.

BEVERINA, Juan. La Guerra del Paraguay 1865-1870 Resumen Histórico. Buenos Aires: Diario La Nación, 1921.

BONAUDO, Marta (dir). Nueva Historia Argentina, Liberalismo, Estado y orden Burgués (1852-1880). Buenos Aires: Editorial Sudamericana, 1999.

BOX, Pelham Horton. Los orígenes de la Guerra del Paraguay contra la Triple Alianza. Buenos Aires: Ediciones Nizza, 1958.

BREZZO, Liliana. Los manuales de historia argentinos y paraguayos. Una aproximación bilateral a las representaciones del Otro. Entrepasados, n. 20-21, 2002.

. La Guerra del Paraguay en los límites de la ortodoxia: mitos y tabúes. Revista Universum, n. 19, vol.1, p 10-27, 2004.

BUCHBINDER, Pablo. Caudillos de pluma y hombres de acción: Estado y política en Corrientes en tiempos de la organización nacional. Buenos Aires: Prometeo, 2004.

CAPDEVILA, Luc. Una guerra total: Paraguay 1864-1870. Ensayo de Historia de Tiempo Presente. Asunción-Buenos Aires: CEADUC-Editorial SB, 2010.

CÁRCANO, Ramón. Guerra del Paraguay, acción y reacción de la triple alianza, dos volúmenes. Buenos Aires: Domingo Viau, 1938. 
CARVALHO, José Murilo de. Brasil. Naciones imaginadas. In: ANNINO, Antonio, CASTRO LEIVA, Luis; GUERRA, Francois Xavier. De los imperios a las naciones: Iberoamérica. Zaragoza: IberCaja, p. 401-422 1994.

CHÁVEZ, Fermín. El revisionismo y las montoneras: la Unión Americana, Felipe Varela, Juan Saá y López Jordán. Buenos Aires: Ediciones Theoria, 1966.

CHIAVENATTO, Julio José. Genocidio americano: a Guerra do Paraguai. San Pablo: Ed Paz e Terra, 1979.

DE LA FUENTE, Ariel. Los hijos de Facundo: caudillos y montoneras en la provincia de La Rioja durante el proceso de formación del Estado Nacional Argentino. Buenos Aires: Prometeo, 2007.

DE MARCO, Miguel Ángel. La Guerra del Paraguay. Buenos Aires: Planeta, 2003.

DORATIOTO, Francisco. Maldita Guerra, Nueva Historia de La Guerra del Paraguay. Buenos Aires: Emecé, 2004.

ESTRADA, José Manuel, Ensayo histórico sobre la revolución de los comuneros del Paraguay y la guerra de 1865. Buenos Aires, 1865.

FRAGOSO, Augusto Tasso. História da guerra entre a Tríplice Aliança e o Paraguai. Rio de Janeiro: Biblex: 1956.

GALASSO, Norberto. Felipe Varela: un caudillo latinoamericano. Buenos Aires: Ediciones Tiempo Latinoamericano, 1975.

Las proclamas de Felipe Varela: el mitrismo y la "Unión Americana.

Buenos Aires: Colihue, 2012.

GÁLVEZ, Manuel. Escenas de la Guerra del Paraguay. Buenos Aires: Editorial La Facultad, 1928-1932.

GARAVAGLIA, Juan Carlos; FRADKIN, Raúl (eds.). Argentina en la Historia. Volumen II. La construcción nacional, 1830-1880. Buenos Aires: Taurus, 2012.

GARCÍA MELLID, Atilio. Proceso a los falsificadores de la guerra del Paraguay. Buenos Aires: Imprenta López, 1964.

KRAAY, Hendrik y WHIGHAM, Thomas (eds). I die with my country. Perspectives on the Paraguayan War, 1864-1870. Studies in War, Society and Military. Lincoln: University of Nebraska Press, 2004.

LOIS, Élida y Paglai, Lucila. Epistolario inédito de Juan Bautista Alberdi y Gregorio Benites (1864-1883). Buenos Aires: UNSAM, 2007.

LÓPEZ, Vicente Fidel. Historia Argentina. Buenos Aires: Carlos Casavalle Editor, 1896.

MAESTRI, Mario. A Guerra no Papel: história e historiografia da guerra no Paraguai. Porto Alegre; Passo Fundo: FCM Editora; PPGHUPR, 2013. 
MASTERMAN, George. Siete años de aventuras en Paraguay. Buenos Aires: Imprenta Americana, 1870.

MITRE, Bartolomé. Guerra del Paraguay. Buenos Aires: La Nación, 1911.

ORTEGA PEÑA, Rodolfo; DUHALDE, Eduardo Luis. Felipe Varela y El Imperio Británico. Buenos Aires: Teoría, 1967.

PALLEJA, coronel León de. Diario de la campaña de las fuerzas aliadas contra el Paraguay. Montevideo: El Pueblo, 1865.

PELLIZA, Mariano. Historia de la organización nacional. Buenos Aires: Félix Lajouane, 1897.

PEÑA, David. Alberdi, los mitristas y la guerra de la Triple Alianza. Estudio preliminar de Ortega Peña y Duhalde. Buenos Aires. Peña Lilo, 1965.

PEÑA, Milcíades. La era de Mitre: de Caseros a la Guerra de la Triple Infamia. Buenos Aires: Fichas, 1968.

POMER, León. La guerra del Paraguay Gran Negocio!. Buenos Aires: Caldén, 1968.

. Cinco años de guerra civil en la Argentina (1865-1870). Buenos Aires: Amorrortu Editores, 1986.

La guerra del Paraguay, Estado, política y negocios. Buenos Aires: Colihue, 2008.

114 POTTHAST-JUTKEIT, Bárbara. ¿Paraíso de Mahoma o país de las mujeres?: el rol de la familia en la sociedad paraguaya del siglo XIX. Asunción: Instituto Cultural Paraguayo-Alemán, 1996.

QUESADA, Ernesto. La política argentino-paraguaya. Buenos Aires: Bredahl, 1902.

QUIÑONEZ, María Gabriela. Historias que nunca se escribieron. Las cautivas, la guerra del Paraguay y la historiografía argentina. In: Terceras Jornadas Internacionales. Historia del Paraguay. Universidad de Montevideo, junio 2012.

RAMÍREZ BRASCHI, Dardo. La guerra de la Triple Alianza a través de los periódicos correntinos. Corrientes: Moglia ediciones, 2004.

REALI, Laura. La revisión de la lectura clásica del conflicto en la producción de Luis A. de Herrera. La Guerra del Paraguay: historiografías, representaciones y contextos. Coloquio anual del CEL. Buenos Aires, 3-5 de noviembre de 2008 disponible en Nuevo Mundo, Mundos Nuevos, Coloquios 2009, http://nuevomundo.revues.org/49363.

RIVAROLA, Milda. La polémica francesa sobre la Guerra Grande. Asunción: Editorial Historica, 1988.

RIVERA, Enrique. José Hernández y La Guerra del Paraguay. Buenos Aires: Editorial Indoamérica, 1954. 
RODRÍGUEZ ALCALÁ, Guido. Residentas, destinadas y traidoras: testimonios de mujeres de la Guerra de la Triple Alianza. Asunción: Editorial Servilibro, 2007.

Ideología Autoritaria. Asunción: Editorial Sevilibro, 2010.

ROMERO, José Luis. Las ideas políticas en Argentina. México: FCE, 1956.

ROSA, José María. La Guerra del Paraguay y las Montoneras argentinas. Buenos Aires: A.Peña, Lilo Editor, 1965.

SABATO, Hilda. Historia de la Argentina: 1852-1890. Buenos Aires: Siglo XXI Editores, 2012.

SALLES, Ricardo. Guerra do Paraguai, escravidão e cidadania na formação do exército. Rio de Janeiro: Paz e Terra, 1990.

SILVEIRA, Mauro César. A Batalha de papel: a chargue como arma na guerra contra o Paraguai. Florianópolis: Editora da UFSC, 2006.

TELESCA, Ignacio (coord). Historia del Paraguay. Asunción: Taurus, 2010.

THOMPSON, George. La Guerra del Paraguay. Buenos Aires: Imprenta Americana, 1869.

TORAL, André. Imagens em Desordem, a iconografia da Guerra do Paraguai (1864-1870). San Pablo: Humanitas FFLCH/USP, 2001.

VIGIL, Mercedes; VALLARINO, Raúl. La Triple Alianza: la guerra contra el Paraguay en imágenes. Montevideo: Planeta, 2007.

WHIGHAM, Thomas. La Guerra de la Triple Alianza, vol I. Causas e inicios del mayor conflicto bélico de América del Sur. Asunción: Taurus, 2010.

La Guerra de la Triple Alianza, vol II. El triunfo de la violencia, el fracaso de la paz. Asunción: Taurus, 2011.

- La Guerra de la Triple Alianza, vol III. Danza de muerte y destrucción. Asunción: Taurus, 2012. 